\title{
Slight free falling impact test for assessing guava maturity
}

\author{
Cheng-Chang Lien ${ }^{1}$, Ching-Hua Ting ${ }^{2 *}$ \\ ${ }^{1}$ Department of Biomechatronic Engineering, National Chiayi University. \\ ${ }^{2}$ Department of Mechanical and Energy Engineering, National Chiayi University; \\ *Corresponding Author: cting@mail.ncyu.edu.tw
}

Received 2013

\begin{abstract}
A non-destructive method for assessing the maturity of guava was developed based on the mechanical properties of the fruit under the slight falling impact test. The levels of maturity were classified with cluster and discriminant analyses on the primitive impact measurements and their derivatives. The accuracy of classification was improved with linear discriminant analysis and the number of indices being processed was reduced with stepwise regression

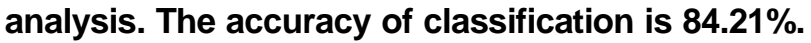
The performance shows that slight falling impact together with linear discriminant analysis provides a promising non-destructive approach in assessing the maturity of guavas.
\end{abstract}

Keywords: Falling impact; Guava; Cluster Analysis; Discriminating Analysis; Stepwise Regression Analysis; Fruit Maturity

\section{INTRODUCTION}

Maturity grading of fruits in harvesting before delivery to the market is beneficial for indicating the optimal time for marketing or for optimisation of storage management $[1,2]$. The maturity of fruit is a qualitative measure, which is difficult to identify. The firmness of a fruit is an index of the mechanical, chemical and rheological properties of the fruit. It is negatively proportional to the maturity of the fruit and can hence be used as an alternative indicator to maturity in fruit grading and sorting [3-4].

The compression and the penetration tests are reliable and traditional methods used to estimate fruit firmness [5] A force-deformation profile is obtained from the test and accordingly, the firmness of the specimen is estimated in reference to the geometrical information of the profile, e.g. the proportional limit, bio-yield strength, and critical strength [5-7]. Several devices related to the classical penetrometer have been developed [8,9]. While many of these proposed techniques result in reasonably accurate and reproducible estimates, they are of a destructive nature, represent mechanical properties at the point of measurement only, and cannot be used as real-time monitoring for fruit sorting.

There are several non-destructive, fast and objective quality measures that have been proposed and some of them are commercially available [4]. Some promising dynamic methods for fruit quality evaluation are based on measurement of fruit response to force vibration or impact [6,9-12]. The use of mass impact [13], either by a light rigid mass or fruit falling, has been widely applied in the detection of fruit maturity. The material is either dropped freely onto a force transducer or hammered with an accelerating rigid mass. The impact responses are interpreted in either the frequency or the time domain. The impact indices show a strong correlation with the firmness of vegetables and fruits [14,15] This method has been used in the detection of the firmness of fruits such as apples [9,16], mangoes [17-19], papayas [20], peaches $[13,18,19]$, and tomatoes $[10,12]$.

Our previous work [12] and other work [18] demonstrate falling impact together with statistical analyses is a simple, effective, efficient fruit maturity assessing technique. Thus, the previous study was expanded for the assessment of psidium guava maturity. A psidium guava is a pear-shape tropical fruit with light green thin skin, white flesh, and hard seeds. In Taiwan, it is consumed as fruit or guava juice. The fruit is rich of proteins and vitamins $\mathrm{A}$ and $\mathrm{C}$. It contains vitamin $\mathrm{C}$ eight times more than orange and $30-80$ times more than watermelon or pineapple. This feature makes it treated as a food in this country. Salient features derived from force responses to falling impact were used as the characterising parameters. Significant characterising parameters are picked using stepwise regression analysis. Results from destructive penetration and compression tests are used as a calibrator. In discriminant analysis, guavas of different maturity classes based on days after fruit harvesting set are graded. 


\section{MEASUREMENT OF FIRMNESS}

\subsection{Apparatus}

Figure 1 illustrates the experimental system developed in the laboratory for investigation into the impact reaction of fruit falling onto a load cell. The apparatus consists of a pneumatic holding mechanism, a load cell and transmitter, a digital oscilloscope, and a computer. A fruit is held by a manually manipulated vacuum sucker and released to fall freely from an adjustable height onto the load cell. The surface of the load cell that receives the impact of the fruit is stainless steel. The vacuum pressure and the falling height are manually adjustable with the rule of thumb of not incurring bruise damage to the fruit, as inadequate mechanical impact may affect the firmness of the guava [21-22].

The load cell (208C02, PCB Piezotronics, NY, USA) is a piezoelectric transducer that generates an analogical signal proportional to the applied force. Its signal is amplified with a 480A09 transmitter (PCB Piezotronics, NY, USA). A digital oscilloscope (2827-02, Bruel\&Kjaer, Demark) digitizes and visualizes the amplified analogue signal and then transmits it to the computer through RS232 serial communication. Data are stored on the computer for subsequent off-line analysis.

\subsection{Conceptual Impact Model}

The mechanical behaviour of a fruitis best modelled with viscoelastic characteristics. The impact of a viscoelastic object onto a rigid obstacle is a complicated phenomenon and could be studied by several different approaches [23]. An impacting fruit is deformable, hence the impact behaviour can be characterised thorough the impacting time, maximal deflection, and impacting forces [24]. Special feature of viscoelastic impacting body is that there exists hysteresis-like behaviour in force-displacement diagram. Such behaviour was explained either by nonlinear models or by use of the standard linear viscoelastic model [25].

Figure 2 demonstrates a typical force response of a guava fruit subject to slight free falling test using the apparatus of Figure 1. The re-bouncing, Dt, defines how long the fruit collides with base structure. A fruits is of viscoelastic characteristics and will deform when impacting onto another subject. This phenomenon can be described as the conversion between potential and kinetic energies. A guava weighing $m$ and falling from height $h$ has the following energy transformation:

$$
m g h=\frac{1}{2} m v^{2}
$$

Where $g$ is the gravitational acceleration and $v$ is the speed of the fruit before colliding.

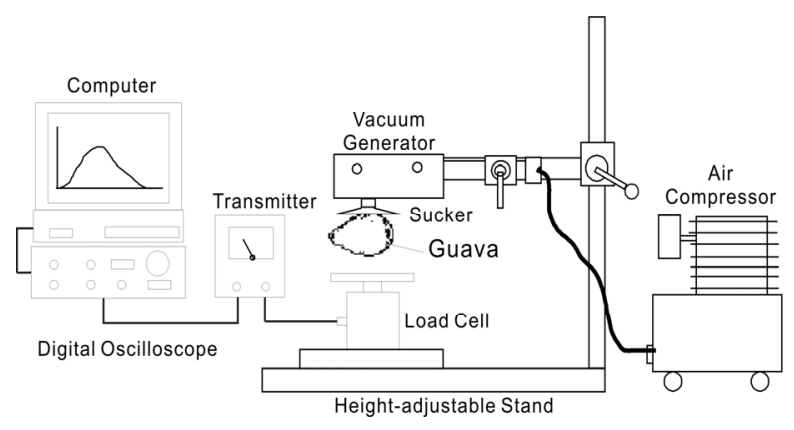

Figure 1. The impact test rig[12].

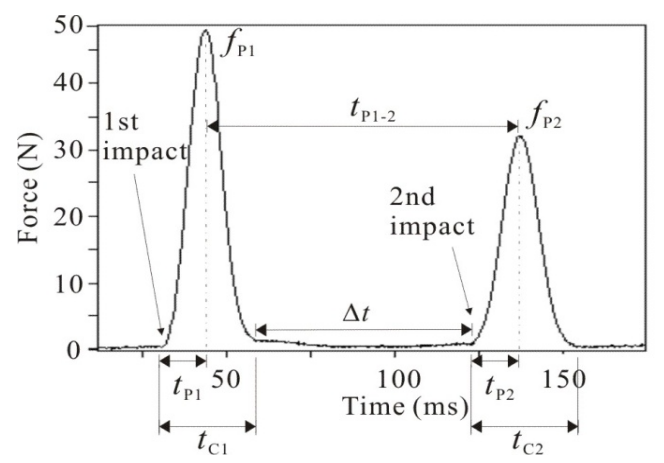

Figure 2. Definitions of impact response.

It is unlikely practical to measure the height, the force, and the velocity. An alternative approach is to characterise the collision through analysing the force response profile. Accordingly, the following indices are proposed for characterising the maturity of guava:

$$
\begin{gathered}
C_{P, 12}=\left(f_{P 1}-f_{P 2}\right) / t_{P 1-2} \\
C_{C, 12}=\left(f_{P 1}-f_{P 2}\right) / \Delta t
\end{gathered}
$$

to transcribe collision with reactive force and colliding time;

$$
\begin{aligned}
& C_{P W, 12}=C_{P, 12} / W \\
& C_{C W, 12}=C_{C, 12} / W
\end{aligned}
$$

to involve the effect of fruit weight.

\subsection{Falling Impact and Fruit Firmness}

The fruit falling on the load cell produces a force that causes a deformation on its flesh. To avoid incurring bruise damage to the fruit, the falling height was adjusted to a distance that does not cause inelastic deformation to the fruit. This non-destructive procedure was validated through the compression test which assures that the peak impact force is far below the bio-yield point of the fruit. The fall on the load cell represents a rheoelastic shock, during which there is a transmission of a certain fraction of the total energy of the fruit onto the surface of the transducer. After the first impact, the fruit suffers a second impact due to the rebound and a new transmission of 
energy is produced. These energy fractions are directly related with the firmness [26].

\section{MATERIALS AND METHODS}

\subsection{Fruit Materials}

Psidium guavas were hand harvested from the same farm at the same time on the day of test. Extremely large and small guavas were rejected. Upon arrival at the laboratory, the guavas were again inspected to ensure that they were uniform, non-damaged and not attacked by worms. The samples were categorised into 4 groups according to the number of post-harvest days, ie. the $1^{\text {st }}$, $3^{\text {rd }}, 5^{\text {th }}$, and $7^{\text {th }}$ day. Hence samples of 4 different maturities were studied.

\subsection{Experimental Procedures}

Each guava sample was sized (precision $0.01 \mathrm{~mm}, 500$ - 196, Mitutoyo, Japan) and weighed (precision $0.1 \mathrm{mg}$, HR-200, A\&D, Japan)immediately after harvesting. Afterwards, the moisture content of some samples from the 4 groups was evaluated. The slight impact test was immediately conducted on the fruit using the apparatus in Figure 1 at a falling height of $15 \mathrm{~mm}$. The height is a compromise between the ease of signal picking by the load cell and causing no bruise damage to the fruit.

The impact measurements provide neither qualitative nor quantitative information about firmness. Hence, the measurements are correlated with the results of the penetration test. The resultant penetration force reflects the lumped mechanical properties of a bio-material $[4,8]$ and can therefore be used as a direct indicator of the firmness of fruit flesh [18,27].

\subsection{Texture Analysis}

The penetration and compression tests were conducted at room temperature on a TA-TX2 Texture Analyser (Texture Technologies Corp., NY, USA). The analyser was calibrated with a $5 \mathrm{~kg}$ weight prior to the first test. It was equipped with a $11 \mathrm{~mm}$ diameter cylindrical stainlesssteel probe for the penetration test and an $80 \mathrm{~mm}$ diameter plate for the compression test. Equipment settings were as follows: test speed, $2 \mathrm{~mm} / \mathrm{s}$; distance, $10 \mathrm{~mm}$ into the guava. Figure $\mathbf{3}$ is a typical force-distance response curve of a guava under penetration test. The curve characterises the firmness of the guava with peak force $F$ and stiffness $K$.

\subsection{Moisture Content}

The moisture content of a guava is determined by placing the sample in an oven of $103^{\circ} \mathrm{C}$ for 24 hours. The moisture content is then calculated by

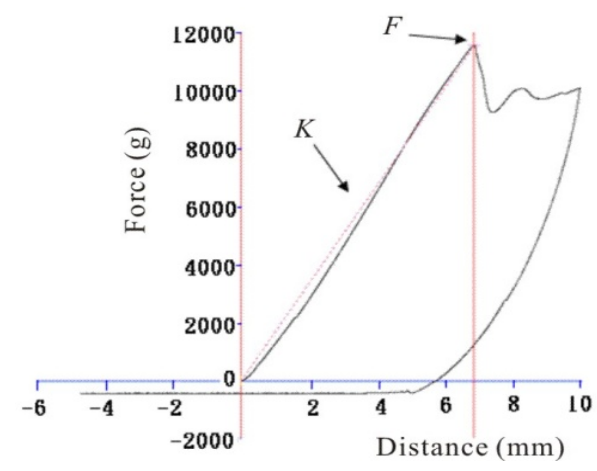

Figure 3. A typical response of penetration test.

$$
w b \%=\left[\left(W_{w}-W_{d}\right) / W_{w}\right] \times 100
$$

where $W_{w}$ is the weight of the guava before drying and $W_{d}$ is the weight of the guava after drying.

\subsection{Data Analysis}

Responses of the penetration test were used as a calibrator for the impact indices and the derivatives. Fruits with various firmness (maturity) under the penetration test were graded with the assistance of cluster analysis. The analysis attempted to correlate the fruit's maturity with its responsive penetration force.

\subsubsection{Cluster Analysis}

The penetration test only indicates the firmness of the guavas samples. The ultimate goal of a sorting system is to classify the guavas into several distinguishable quality groups. Hence, cluster analysis (CA) was introduced to classify the fruits, according to experimental measurements, into different maturity groups (clusters). The measurements in each group share some common traits according to some defined distance measures. CA is used to search for natural grouping trends among samples into fourripeness levels (aka the number of post-harvest days). The FASTCLU procedure of the SAS statistical software (V8, SAS Institute Inc., NY, USA) was used.

\subsubsection{Analysis of Primitive Measurements}

The primitive impact measurements give direct information about the mechanical properties of the fruit. They are determined by the firmness and the weight of the fruit. These measurements may provide redundant or insignificant information in identifying the level of ripeness. Hence, the Scheffe test was used to compare the significance of each variable among the four groups of ripeness. The test determines which specific groups are significantly different in statistics. The Scheffe test was performed using the SAS ANOVA procedure.

\subsubsection{Linear Discriminant Analysis}

Linear discriminant analysis (LDA) is a statistical tech- 
nique to classify individuals or objects into mutually exclusive and exhaustive groups on the basis of a set of independent variables. LDA is used to find an optimum linear combination of the independent variables that minimises the probability of misclassifying fruits into their respective groups. The variables used in computing the linear discriminant functions are chosen in a stepwise manner, both forward and backward, using the SAS STEPDISC procedure. At each step, the variable that adds most to the separation of the classes is entered into (forward) or the variable that adds least is removed from (backward) the discriminant function. The SAS DISCRIM procedure was used to perform discriminant analysis to classify the guavas into classes of test response. If a fruit is classified into the same class of test response and origin, e.g. a ripe guava (origin) is classified into the ripe class of test response, this guava is identified as well classified.

\section{RESULTS AND DISCUSSION}

\subsection{Primitive Measurements}

Table 1 summarises the physical properties of the guava fruits examined immediately after harvesting. The level of maturity can be characterised by the peak penetrating force, $F$, and the stiffness, $K$, as defined in Figure 3. The results of penetration test of guavas with different maturities are shown in Table 2. Clearly, the number of days of post-harvest affects the maturity of guava significantly. The penetration test is therefore used as a reference for calibrating the accuracy of maturity identification using the impact test.

Table 1. Physical properties.

\begin{tabular}{lccc}
\hline & $\begin{array}{c}\text { Weight } \\
(\mathrm{g})\end{array}$ & $\begin{array}{c}\text { Average Diameter } \\
(\mathrm{mm})\end{array}$ & $\begin{array}{c}\text { Moisture Content } \\
(\%)\end{array}$ \\
\hline Samples & 38 & 38 & 24 \\
Average & 323.86 & 83.87 & 87.69 \\
Std. Dev. & 79.97 & 3.67 & 1.40 \\
Variance & 0.24 & 0.04 & 0.02
\end{tabular}

${ }^{\mathrm{a}}$ Variance $=$ standard deviation/average.

Table 2. Penetration measurements of guavas after days of harvesting.

\begin{tabular}{ccccc}
\hline & Day 1 & Day 3 & Day 5 & Day 7 \\
\hline Samples & 38 & 38 & 38 & 38 \\
$F$ & $11747 \pm 2228^{\mathrm{a}}$ & $11548 \pm 2450^{\mathrm{a}}$ & $10391 \pm 3002^{\mathrm{a}}$ & $7853 \pm 3448^{\mathrm{b}}$ \\
$K$ & $2228 \pm 493^{\mathrm{a}}$ & $1703 \pm 389^{\mathrm{b}}$ & $1204 \pm 362^{\mathrm{c}}$ & $904 \pm 378^{\mathrm{d}}$ \\
\hline
\end{tabular}

Values are in mean $\pm \mathrm{SD}$. At the same row, values with different superscripts aresignificantly different $(\mathrm{P} \leq 0.05)$ in means by the Scheffé test.

\subsection{Penetration Test as a Calibrator}

All samples were classified into distinguishing clusters with cluster analysis of the penetration force $K$. Table 3 lists the result of cluster analysis using the SAS FASTCLU procedure. It is understandable that a riper sample can easily be penetrated with a smaller force, as maturation causes a slight softening in such a guava than in a less mature one [28]. The automated FASTCLU procedure classified the samples into 6 distinguishing clusters. However, the use of 6 levels of maturity is considered too many and cumbersome in practice [12]. Thus, the 6 clusters are further transcribed to 3 groups by combining any two clusters which have the closest mean penetration forces. Table 4 summarises the information about the transcribed three maturity groups.

\subsection{Adequate Indices}

Stepwise regression analysis (SAS STEPDISC) was used to find out the most significant factors among the bulky number of candidate indices in maturity classification. The analysis revealed that $f_{P 2} / f_{P 1}, C_{P W, 12}$, and $f_{P 1}-f_{P 2}$ are the three most dominant indices, with analytical results summarised in Table 5.

Table 3. Guavas in 6 clusters by cluster analysis of the stiffness $K(\mathrm{~g} / \mathrm{mm})$ from penetration test.

\begin{tabular}{ccccc}
\hline Group & Samples & Mean & Standard Deviation & Closest Cluster \\
\hline 1 & 1 & 3516.4 &. & 2 \\
2 & 9 & 2743.57 & 144.38 & 6 \\
3 & 47 & 1572.15 & 199.91 & 5 \\
4 & 14 & 476.36 & 148.19 & 5 \\
5 & 48 & 1021.31 & 153.93 & 4 \\
6 & 33 & 2175.39 & 172.44 & 2 \\
\hline
\end{tabular}

Table 4. Guava in 3 groups of maturity transcribed from the 6 CA clusters from cluster analysis of the stiffness $K(\mathrm{~g} / \mathrm{mm})$.

\begin{tabular}{ccccc}
\hline Maturity & Samples & Mean & Standard Deviation CA clusters \\
\hline A & 62 & 898.26 & 275.14 & 4,5 \\
B & 47 & 1572.15 & 199.91 & 3 \\
C & 43 & 2325.50 & 339.90 & $1,2,6$ \\
\hline
\end{tabular}

Table 5. Statistics of the most significant impact indices by stepwise regression analysis.

\begin{tabular}{clccc}
\hline Step & Index & PartialR-square & $F$ Value & $\operatorname{Pr}>F$ \\
\hline 1 & $f_{P 2} / f_{P 1} \#$ & 0.5271 & 83.03 & $<0.0001$ \\
2 & $C_{P W, 12} \#$ & 0.1706 & 15.22 & $<0.0001$ \\
3 & $f_{P 1}-f_{P 2} \#$ & 0.0649 & 5.1 & 0.0072 \\
\hline
\end{tabular}


The three indices contain collision force, which has significant difference in the mean values of all three classes of maturity as shown in Table 6. The analysis also reveals that the weight $W$ is an important factor of using falling impact test in estimation of guava maturity. The methodology can arrive at an estimation accuracy of $77.4 \%$ using the three indices.

\subsection{Validation with Post-harvest Ripening}

The ripeness of a fruit is proportional to the number of post-harvest days. Samples at 1st, 3rd, 5th, and 7th post-harvest days should have 4 different maturities. Table 7 lists the 5 most significant impact indices, obtained through stepwise regression analysis, for identifying the maturity of guava categorised by the number of postharvest days. The methodology can arrive at an estimation accuracy of $84.21 \%$, as shown in Table 8 .

\subsection{Assurance of Non-Destructive Test}

Possible bruise damage by falling impact was inspected by visual inspection and mechanical analysis. Guava samples of various post-harvest daywere randomly selected for the compression test. The bio-yield points of the four fruit maturities counted by post-harvest days are all around $20000 \mathrm{~g}(196 \mathrm{~N})$. The maximum impact force shown is $88.45 \mathrm{Nfar}$ below $196 \mathrm{~N}$, the bioyield points. Hence, the impact test does not develop inelastic deformation to the fruits.

\section{Conclusions}

The slight falling impact method is feasible in firmness measurement and hence in classification of the guava maturity in compliance with numbers of postharvestdays. The falling induces an impact force to the fruit, which can be easily adjusted to such a level that

Table 6. Accuracies of tomato classification using derived impact indices.

\begin{tabular}{ccccc}
\hline Samples & MaturityA & Maturity B & Maturity C & Total \\
\cline { 2 - 4 } & 62 & 47 & 43 & 152 \\
\hline$f_{P 2} / f_{P 1}$ & $48(77.42 \%)$ & $23(48.94 \%)$ & $32(74.42 \%)$ & $103(66.92 \%)$ \\
$f_{P 2} / f_{P 1}, C_{P W, 12} \#$ & $42(67.74 \%)$ & $31(65.96 \%)$ & $38(88.37 \%)$ & $111(74.02 \%)$ \\
$f_{P 1}-f_{P 2} \#$ & $43(69.35 \%)$ & $35(74.47 \%)$ & $38(88.37 \%)$ & $115(77.40 \%)$ \\
\hline
\end{tabular}

Table 7. Statistics of the most significant impact indices by stepwise regression analysis.

\begin{tabular}{cccc}
\hline Index & PartialR-square & $F$ Value & $\operatorname{Pr}>F$ \\
\hline$f_{P 2} / f_{P 1}$ & 0.772 & 167.05 & $<0.0001$ \\
$f_{P 1}-f_{P 2} \#$ & 0.125 & 6.98 & 0.0002 \\
$t_{C 1}-t_{C 2} \#$ & 0.069 & 3.61 & 0.015 \\
$C_{P W, 12} \#$ & 0.097 & 5.17 & 0.002 \\
$t_{C 2} / t_{C 1}$ & 0.172 & 9.93 & $<0.0001$ \\
\hline
\end{tabular}

Table 8. Accuracies of guava classification using discriminant analysis of two re-bouncing reponses.

\begin{tabular}{|c|c|c|c|c|c|}
\hline Samples (accuracy\%) & Day 1 & Day 3 & Day 5 & Day 7 & Total \\
\hline$f_{P 2} / f_{P 1}$ & $31(81.58 \%)$ & $22(57.89 \%)$ & $25(65.79 \%)$ & $31(81.58 \%)$ & $109(71.71 \%)$ \\
\hline$f_{P 2} / f_{P 1}, f_{P 1}-f_{P 2}$ & $35(92.11 \%)$ & $26(68.42 \%)$ & $27(71.05 \%)$ & $31(81.58 \%)$ & $119(78.29 \%)$ \\
\hline$f_{P 2} / f_{P 1}, f_{P 1}-f_{P 2}, \Delta T$ & $35(92.11 \%)$ & $25(65.79 \%)$ & $28(73.68 \%)$ & $32(84.21 \%)$ & $120(78.95 \%)$ \\
\hline$f_{P 2} / f_{P 1}, f_{P 1}-f_{P 2}, \Delta T, C_{P W, 12}$ & $36(94.74 \%)$ & $30(78.95 \%)$ & $30(78.95 \%)$ & $29(76.32 \%)$ & $125(82.24 \%)$ \\
\hline$f_{P 2} / f_{P 1}, f_{P 1}-f_{P 2}, \Delta T, C_{P W, 12}, t_{C 2} / t_{C 1}$ & $38(100 \%)$ & $30(78.95 \%)$ & $28(73.68 \%)$ & $32(84.21 \%)$ & $128(84.21 \%)$ \\
\hline
\end{tabular}


does not damage the fruit. The primitive measurements of impact test do not give substantial information about the classification of guava maturity. The accuracy of classification can be improved by performing CA and LDA on derived indices. The accuracy reaches $77.4 \%$ with the stiffness $K$ as a calibrator from textural analysis and $84.21 \%$ with post-harvest days as a calibrator. However, a method with an accuracy of classification better than $75 \%$ is good enough for practical application [19]. Hence, this laboratory study encourages the use of fall.

\section{ACKNOWLEDGEMENTS}

This study is partially sponsored by National Science Council of Taiwan under a grant no. NSC-101-2221-E-415-014.

\section{REFERENCES}

[1] Wu, T. and Abbott, J.A. (2002) Firmness and force relaxation characteristics of tomatoesstored intact or as slices. Postharvest Biology and Technology, 59, 59-68. doi:10.1016/S0925-5214(01)00133-8

[2] Singh, K.K. and Reddy, B.S. (2006) Post-harvest physco-mechanical properties of orangepeel and fruit. Journal of Food Engineering, 73, 112-120. doi:10.1016/j.jfoodeng.2005.01.010

[3] Mohsenin, N.(1986) Physical Properties of Plant and Animal Materials, second ed. Gordon and Breach, New York, USA.

[4] De Ketelaere, B., Howarth, M.S., Crezee, L., Lammertyn, J., Viaene, K., Bulens, I. and DeBaerdemaeker, J. (2006) Postharvest firmness changes as measured by acousticand low-mass impact devices:a comparison of techniques. Postharvest Biologyand Technology, 41, 275-284. doi:10.1016/j.postharvbio.2006.04.008

[5] ASAE(1993) Compression test food materials of convex shape. In: ASAE Standards. ASAE, St. Joseph, Michigan, Ch. S368.2, pp. 451-455.

[6] Delwiche, S.R. (2000) Wheat endosperm compressive strength properties as affectedby moisture. Transaction of the ASAE, 43, 365-373.

[7] Fidelibus, M.W., Teixeira, A.A. and Davies, F.S. (2002) Mechanical properties of orangepeel and fruit treated pre-harvest with gibberellic acid. Transaction of the ASAE45, 1057-1062.

[8] Abbott, J.A.(1999) Quality measurement of fruits and vegetables. Postharvest Biology and Technology, 15, 207-225. doi:10.1016/S0925-5214(98)00086-6

[9] Peleg, K. (1999) Development of a commercial fruit firmness sorter. Journal ofAgricultural Engineering Research, 72, 231-238.

[10] De Ketelaere, B. and de Baerdemaeker, J. (2001) Tomato firmness estimation usingvibration measurements. Mathematics and Computers in Simulation, 56, 385-394. doi:10.1016/S0378-4754(01)00309-3

[11] Jarén, C. and Garczía-Pardo, E. (2002) Using non-de- structive impact testing for sortingfruits. Journal of Food Engineering, 53, 89-95.

doi:10.1016/S0260-8774(01)00144-3

[12] Lien, C. C., C. Ay and C. H. Ting. (2009) Non-destructive impact test for assessment of tomato maturity. Journal of Food Engineering, 91, 402-407.

doi:10.1016/j.jfoodeng.2008.09.036

[13] Delwiche, M.J., McDonald, T. and Bowers, S.V. (1987) Determination of peach firmnessby analysis of impact forces. Transaction of the ASAE, 30, 249-254.

[14] Brusewitz, G.H., Mccollum, T.G. and Zhang, X.(1991) Impact bruise resistance ofpeaches. Transactions of the ASAE, 34, 962-965.

[15] García-Ramos, F.J., Navate, J.O.-C., Ruiz-Altisent, M., Díez, J., Flores, L., Homer, I. and Chávez, J. (2003) Development and implementation of an on-line impact sensorfor firmness sensing of fruits. Journal of Food Engineering, 58, 53-57. doi:10.1016/S0260-8774(02)00333-3

[16] Shmulevich, I., Galili, N. and Howarth, M.S. (2003) Nondestructive dynamic testing ofapples for firmness evaluation. Postharvest Biology and Technology, 29, 287-299. doi:10.1016/S0925-5214(03)00039-5

[17] Hahn, F.(2004) Mango firmness sorter. Biosystems Engineering, 89, 309-319. doi:10.1016/j.biosystemseng.2004.07.005

[18] Wang, J., Teng, B. and Yu, Y. (2006) The firmness detection by excitation dynamic characteristics for peach. Food Control, 17, 353-358. doi:10.1016/j.foodcont.2004.12.001

[19] Gutierrez, A., Burgos, J.A. and Molto, E.(2007) Pre-commercial sorting line for peachesfirmness assessment. Journal of Food Engineering, 81, 721-727. doi:10.1016/j.jfoodeng.2007.01.006

[20] Reyes, M.G., Paull, R.E., Williamson, M.R. and Gautz, L.D. (1996) Ripeness determinationof "solo" papaya (Carica Papaya L.) by impact forces. Applied Engineering in Agriculture, 12, 703-708.

[21] Van linden, V., Scheerlinck, N., Desmet, M. and De Baerdemaeker, J. (2006) Factors thataffect tomato bruise development as a result of mechanical impact. PostharvestBiology and Technology, 42, 260-270.

[22] Arazuri, S., Jarén, C., Arana, J.I. and Pérez de Ciriza, J.J.( 2007) Influence of mechanical harvest on the physical properties of processing tomato (Lycopersicon esculentum Mill). Journal of Food Engineering, 80, 190-198. doi:10.1016/j.jfoodeng.2006.05.008

[23] Atanackovic, T. M., Spasic D. T. (2004) On Viscoelastic Compliant Contact-Impact Models. Journal of Applied Mechanics, 71, 134-138. doi.org/10.1115/1.1629106

[24] Brogliato, B. (1999) Nonsmooth Dynamics. Springer, London.

[25] Butcher, E. A. and Segalman, D. J. (2000) Characterizing Damping and Restitution in Compliant Impact via ModiRed K-V and Higher Order Linear Viscoelastic Models. Journal of Applied Mechanics, 67, 831-834. doi:10.1115/1.1308578

[26] Chen, H. and De Baerdemaeker, J.(1995) Optimization of impact parameter for reliableexcitation of apples during 
firmness monitoring. Journal of Agricultural Engineering Research, 61, 275-282. doi:10.1006/jaer.1995.1055

[27] Grotte, M., Duprat, F., Loonis, D. and Piétri, E. (2001) Mechanical properties of the skinand the flesh of apples.
International Journal of Food Properties, 4, 149-161.

[28] Batu, A.(2004) Determination of acceptable firmness and colour values of tomatoes. Journal of Food Engineering, 61, 471-475. doi:10.1016/S0260-8774(03)00141-9 